http://dx.doi.org/10.1590/0104.026X2015v23n3p1038

\title{
Feminismo: aporte político, teórico e prático para transformações civilizatórias
}

\section{Feminismo para un cambio civilizatorio. \\ CAROSIO, Alba (Org.).}

Caracas: Fundación Centro de Estudios Latinoamericanos Rómulo Gallegos, Consejo Latinoamericano de Ciencias Sociales y Centro de Estudios de la Mujer, Universidad Central de Venezuela, 2014. 301 p.

(c) $\odot$ Esta obra tem licença Creative Commons.

O livro Feminismo para um cambio civilizatório foi elaborado a partir da inserção acadêmica e política de feministas reconhecidas por suas trajetórias, sendo referência na construção de teorias e propostas feministas no contexto do pensamento latino-americano e caribenho.

É reflexo também de profundos e intensos debates no Grupo de Trabalho do CLACSO "Feminismo y cambio social en America Latina y Caribe", sendo esta a quarta publicação do grupo, que vem se desenvolvendo desde 2007.

O livro foi coordenado por Alba Carosio, licenciada e mestre em Filosofia e doutora em Ciências Sociais pela Universidade Central de Venezuela, Diretora e Coordenadora de Investigação do Centro de Estudos da Mulher, na Universidade Central de Venezuela, Editora da Revista Venezolana de Estudos da Mulher. Além disso, tem valiosa contribuição no que tange à história do feminismo e às três diferentes ondas construídas na América Latina e Caribe.

O objetivo desse livro é servir como aporte político, teórico e prático para transformações civilizatórias, por meio da construção de éticas alternativas de vida e do conceito do bem-viver, isto é, a realização da justiça social, entendendo que, nas sociedades capitalistas, a destruição da vida é latente e avança mediante a colonização mercantil de todos os aspectos e espaços do humano e do natural potencializados por um forte aliado que é o patriarcado.

Define-se, então, nesse livro, o capitalismo como modelo civilizatório, patriarcal e racializado, que está baseado na discriminação e hierarquização, dois elementos úteis à exploração e acumulação. Nesse modelo, se estabelece a superioridade e o domínio do modelo masculino de vida social, baseados na desvalorização do modo feminino de ser, estar e construir o mundo, o que leva a divisão sexual do trabalho centrada na competência e agressividade que faz a seguinte divisão: público/masculino e privado/feminino, e nega a interdependência dos âmbitos público e privado, invisibilizando, assim, metade da população mundial. O capitalismo impõe a preeminência da produção para acumulação cada vez mais abstrata e separada das necessidades dos corpos concretos, tornando importante somente aquilo que contribui para a realização de maisvalia e construindo uma série de ideias e valores como individualismo, competência, dominação e consumo, o que gera práticas sociais e estilos de vida funcionais ao capital. As feministas radicais demonstraram que, na história da educação masculina, os homens tornam-se competitivos, racionalistas e dominantes, o que coincide com a descrição dos valores da sociedade capitalista. Paralelamente, se desvaloriza/invisibiliza o trabalho concreto feminino de reprodução/ produção, gerando e ocultando o conjunto de opressões que sofrem as mulheres, no sentido também de tornar essas opressões como algo natural e, portanto, impossível de ser emancipado. Tudo isso se observa de maneira devastadora na violência contra as mulheres, a feminização planetária da pobreza, a comercialização dos 
corpos femininos em diferentes formas, a discriminação e opressão da sexualidade, a desvalorização do conhecimento produzido pelas as muIheres, a segregação laboral, a masculinização das estruturas de poder etc.

O racismo, por sua vez, é mais um sistema de controle que parte de um modo de hierarquização baseado em converter um conceito polííico dos traços físicos, justificando a dominação e opressão. O livro conceitua raça como uma construção que expressa a experiência básica da dominação colonial, serve como um conjunto sistemático entre opressor e oprimido, o que ajuda também o capitalismo, proporcionando mão de obra discriminada e, portanto, mais barata, isso estimula a divisão da classe trabalhadora e suas lutas.

Hipocritamente, o capitalismo, em especia - liberal e neoliberal, simula igualar todas as pessoas num livre jogo de mercado diante da sua "neutralidade". A desigualdade está baseada, então, numa condição de mérito e, assim, nota-se a falácia do capitalismo de que qualquer um pode progredir nesse sistema. A argumentação da desigualdade material é que só é possível garantir a igualdade de oportunidades diante da igualdade perante a lei.

Nesse sentido, a autora apresenta raça e sexo, tanto quanto classe, como categorias políticas que implicam discriminação e opressão. As diferenças de sexo, não menos que as de raça, são construídas ideologicamente para legitimar a desigualdade social, dando-lhe base material e estrutura social as condições hierárquicas que justificam a exclusão e exploração. Trata-se de dispositivos políticos que naturalizam a opressão, atribuindo a culpa de sua inferioridade às próprias vítimas. $\mathrm{E}$ são as condições da estrutura da sociedade de classe que fazem dela também patriarcal e racialmente estruturada.

Raça e sexo determinam a divisão social e internacional do trabalho, definindo, então, o modelo civilizatório em que se articula patriarcado, racismo e também colonialidade, gerando um modo de vida com múltiplos entrecruzamentos de poderes e desigualdades. Desde os feminismos, a proposta transformadora é também a de recuperar princípio e modo feminino, concretizado nas ações coletivas das mulheres para transformação social.

Como afirma Magdalena Valdivieso, as perspectivas feministas constituem uma poderosa corrente subversiva contra o padrão de poder que tem levado a humanidade ao limite da sobrevivência. Pensando a partir da América Latina e do Caribe, nota-se suas diversidades vibrantes de transformações e também de retrocessos.

Assim, nesse livro, o Grupo de Trabalho de Feminismos se dedica a análises e propostas que respondam a problemas e demandas antigas $e$ novas, desde a justiça e a emancipação das mulheres historicamente concretas em articulação com movimentos sociais, coletivos populares e Estados em construção.

O livro está agrupado em quatro seções, determinadas por linhas temáticas. A primeira seção, intitulada "Alternativas desde el feminismo", está centrada na discussão integral das alternativas que os feminismos em América Latina e Caribe vêm refletindo e propondo. Com o texto "Otros tiempos y otros feminismos en América Latina y el Caribe", Magdalena Valdivieso, do Chile, faz uma análise da história dos feminismos latino-americanos desde os anos 60, debatendo seus (des)encontros e desafios atuais.

O texto seguinte, escrito por Monstserrat Sagot, da Costa Rica, chamado "La democracia en su laberinto: el neoliberalismo y los límites de la acción política feminista en Centroamérica", apresenta a geolocalização centro-americana, faz uma crítica à contradição entre a promessa da democracia e a paz e as condições de vida desesperadas que enfrentam importantes setores da população no contexto do surgimento de grupos organizados de caráter religioso e conservador.

Eugenia Correa, do México, apresenta "Sociedad patriarcal, las luchas por la equidad de género y el posneoliberalismo", em que discute os elementos centrais da sociedade patriarcal que se fortaleceram durante a era neoliberal, contrapondo a proposta ética feminista indispensável para a era pós-neoliberal.

A segunda seção: "Análisis feministas de las políticas y el cambio" inclui trabalhos que elaboram análises e propostas de políticas públicas em desenvolvimento na América Latina e Caribe. O texto inicia com o debate de Alba Carosio, da Venezuela, "Mujeres y género en las políticas sociales latino-americanas", que mostra as políticas sociais de esquerda que têm como centro as mulheres e estabelece algumas conclusões sobre suas aportações a transformações e à justiça social.

Em seguida, o texto "Cubanas, Buen Vivir y percepción de los cambios socioeconómicos", de Norma Vasallo Barrueta, de Cuba, analisa as transformações em Cuba desde a percepção e a subjetividade das mulheres em diálogo com a proposta do bem-viver.

Alicia Girón, do México, debate "Neoliberalismo, microcréditos y empoderamiento de las 
mujeres", em que examina por que os microcréditos não têm sido, necessariamente, o veículo para melhorar as relações de equidade entre homens e mulheres, além de fazer relação entre os microcréditos e a macroeconomia, para explicar como o empoderamento das mulheres não está associado somente à obtenção de créditos. mas à possibilidade de inserção, como empreendedoras, nas decisões administrativas, políticas e sociais.

Seguindo esse enfoque econômico, a Méxicana Alejandra Arroyo contribui com o texto "Una alternativa para las mujeres en la crisis económica en la era de la sociedad de la información y el conocimiento", para debater as tecnologias da informação e comunicação (TICs), para as políticas de estímulo ao empreendimento feminino.

A terceira seção, intitulada "Luchas laborales para el cambio social", apresenta as lutas trabaIhistas das mulheres e a prefiguração das transformações sociais que nasce em seu processo. Nessa seção, está o trabalho "'No vamos atrás de nadie'. La experiencia de las obreras de lamultinacional Kraft (Mondelez) en Argentina", da Argentina María Chaves, que indaga a significação como conjunção da luta contra exploração de classe e a opressão de gênero, seguido do trabalho "Sindicato y mujeres. El caso de Mexicana de Aviación", da autoria de María Luisa Gónzález Marín y Mariana Martínez García, do México, que, em contraposição ao trabalho anterior, revela o caso da Asociación Sindical de Sobrecargos de Aviación, em que evidenciam as diûculdades que têm as mulheres para expor e trabalhar suas demandas.
A quarta seção, intitulada "Sexualidad y transformación social", trata da sexualidade e a eliminação das opressões das mulheres em âmbito constituinte da transformação social. Com o trabalho "Despatriarcalizar la atención sanitaria: el asunto de fondo para garantizar el derecho a la vida en Venezuela", Elisa Alejandra Valdivieso expõe de maneira intensa a realidade e consequência do patriarcado que intervém na atenção sanitária na Venezuela.

Em Seguida, Lucy Mirtha Ketterer Romero, do Chile, apresenta seu trabalho intitulado "Derechos sexuales y derechos reproductivos en La Araucanía: experiencias de desigualdades y resistências", no qual explica os processos de dominação/resistência na prática dos direitos sexuais e reprodutivos das mulheres mapuches da região da Araucanía, no sul do Chile.

Por fim, Raquel Drovetta, da Argentina, nos brinda com o texto "Acciones feministas en las Líneas de Información Aborto Seguro (LIAS) en Latinoamérica y el Caribe", apresentando um estudo detalhado das realidades e lutas pelo direito ao aborto, desde ações feministas e sua prática política.

Esse conjunto de reflexões e debates instigantes apresenta-nos uma variedade de rostos cobre, ébano e mel de mulheres que são sujeitas na transição para sociedades mais justas $e$, a partir de seus trabalhos e organizações, vão gestando transformações sociais, construindo feminismos que abarquem a nossa diversidade latinoamericana.

Laiany Rose Souza Santos Universidade Federal de Sergipe

1040 Estudos Feministas, Florianópolis, 23(3): 1023-1044, setembro-dezembro/2015 